\title{
Analysis and Research of the High-Cycle Fatigue Fracture Mode Based on Stress Ratio and Residual Stress of Ti-6Al-4V
}

\author{
Fu Wang $\mathbb{D},{ }^{1}$ Jian-Jun Wang $\mathbb{D},{ }^{1,2}$ Qin-Sheng Li, ${ }^{1}$ Guo-Zhu Ren, ${ }^{3}$ Xin-Jian Zhang, ${ }^{1}$ \\ and Shu-quan Zhang ${ }^{4}$ \\ ${ }^{1}$ School of the Mechanical Engineering, Anhui Technical College of Mechanical and Electrical Engineering, Wuhu 241002, China \\ ${ }^{2}$ School of the Mechanical Engineering, Yanshan University, Qinhuangdao 066004, China \\ ${ }^{3}$ Engineering Technology Training Centre, Beihua Aerospace Engineering College, Langfang, Hebei 065000, China \\ ${ }^{4}$ Institute of Plasma Physics, Chinese Academy of Sciences, Hefei 341000, China
}

Correspondence should be addressed to Fu Wang; 707647204@qq.com

Received 5 March 2021; Revised 3 December 2021; Accepted 14 December 2021; Published 12 January 2022

Academic Editor: Abílio De Jesus

Copyright (C) $2022 \mathrm{Fu}$ Wang et al. This is an open access article distributed under the Creative Commons Attribution License, which permits unrestricted use, distribution, and reproduction in any medium, provided the original work is properly cited.

\begin{abstract}
The content of titanium is about $0.63 \%$ in the earth's crust, and it ranks 10th among all elements. The content of titanium is next to the metal elements of aluminum, iron and magnesium, iron, and magnesium; titanium alloys have low density, high specific strength (the ratio of tensile strength to density), wide working range $\left(-253^{\circ} \mathrm{C}-600^{\circ} \mathrm{C}\right)$, and excellent corrosion resistance melting point; the chemical activity of titanium alloy is very high, and it easily reacts with hydrogen, oxygen, and nitrogen, so it is difficult to be smelted and processed, and the processing cost is high. Titanium alloys also have poor thermal conductivity (only $1 / 5$ of iron and 1/15 of aluminum), small deformation coefficient, large friction coefficient, and other characteristics. They are widely used in aircraft fuselage, gas turbine, petrochemical, automotive industry, medical, and other fields for important parts.
\end{abstract}

\section{Introduction}

The titanium content is about $0.63 \%$ in the earth's crust, and it ranks 10th among all elements [1]. The content of titanium is next to the metal elements of aluminum, iron and magnesium, iron, and magnesium; titanium alloys have low density, high specific strength (the ratio of tensile strength to density), a wide working range $\left(-253{ }^{\circ} \mathrm{C}-600{ }^{\circ} \mathrm{C}\right)$, and excellent corrosion resistance melting point; the chemical activity of titanium alloy is very high. It easily reacts with hydrogen, oxygen, and nitrogen. Therefore, it is challenging to smelt and process, and the processing cost is high. It is widely used in aircraft fuselage, gas turbines, petrochemicals, automotive industry, medical, and other fields for important parts [1]. However, titanium alloy parts' high-cycle fatigue capacity has been one of the unsolved problems in development and application [1-5].The high-cycle fatigue strength of Ti-6Al-4V has been studied intensely by some domestic and foreign scholars. The results show that different from low-cycle fatigue, the high-cycle fatigue crack of titanium alloy tends to be internal, and the fracture surface is circular. Some scholars believe that the process of crack nucleation mainly controls high-cycle and ultra-high-cycle fatigue failure, and the microdeformation between the soft primary $a$ phase and complex $\beta$ phase in the dual-phase microstructure of Ti-6Al-4V is analyzed by software; the results show that it is easy to form the fatigue source in the soft primary $a$ phase $[6,7]$. Some researchers have carried out high-cycle fatigue tests on three different titanium alloys $[8,9]$. The results show that the fatigue fracture surface of titanium alloy has a large area of adjacent small planes, most of which are near the base surface. It is favorable for the grain direction of crack initiation, and the loading direction is $15^{\circ}-40^{\circ}$. Besides the high-cycle fatigue or ultra-high-cycle fatigue, internal cracking also has the typical characteristics of good surface quality and residual compressive stress field [10-13]. Titanium alloys' residual stress and microstructure evolution caused by turning, shot peening, laser shot peening, and deep rolling have been widely studied. The mechanism of surface strengthening is mainly due to the 
introduction of residual stress, work hardening, microstructure refinement, and surface roughness reduction. Although the effect of residual compressive stress on fatigue strength has been widely accepted, most of the research focuses on the case of stress ratio $R=-1.0$. The relaxation and redistribution of the surface residual compressive stress layer under different fatigue load ratios and the effect on fatigue strength under different stress ratios are yet to be studied.

In this study, the fatigue tests of Ti-6Al-4V alloy were carried out under five stress ratios $(R=-1.0,-0.6,-0.3,-0.1$, and 0.6 ), which were machined by turning and heat-treated by eliminating stress; the effects of stress ratio on residual stress release and the effect of stress ratio and residual stress on high-cycle fatigue strength fracture mode are studied.

\section{Materials}

The chemical composition of the titanium alloy Ti-6Al-4V bar is shown in Table 1 . The microstructure of Ti-6Al-4V is shown in Figure 1. The volume fraction of the $a$ phase is $88 \%$, and the width of the $a$ lamellae is $3 \sim 4 \mu \mathrm{m}$. The yield strength and tensile strength at room temperature are $882 \mathrm{MPa}$ and $933 \mathrm{MPa}$, respectively.

A smooth axial fatigue specimen is prepared according to ASTM e 466-2007 in shape and size as shown in Figure 2. The samples were processed by two methods: turning and axial polishing, first turning and then polishing, and the processing process was as follows: $\Phi 15 \times 111 \mathrm{~mm}$ roughcast to $\varphi 14.2 \times 110 \mathrm{~mm}$, then semifinishing to $\varphi 14.04 \times 110 \mathrm{~mm}$, middle to $\Phi 5.44 \mathrm{~mm}$, and arc to R75, the specimen is then chamfered at both ends, and finally, the specimen is polished and polished with stress-free heat treatment except at both ends to meet the size requirements shown in Figure 2. The measured value of the specimen surface roughness is shown in Table 2. The heat treatment process is as follows: the sample is suspended in a vacuum furnace (the vacuum degree is $2.8 \times 10^{-3} \mathrm{PA}$ ) and slowly heated to $600^{\circ} \mathrm{C}$ for 3 hours and then slowly cooled with the furnace.

\section{Methods of Test and Measurement}

The fatigue tests of Ti-6Al-4V specimens with turning residual stress and the specimens after stress relief treatment were carried out at room temperature and air, respectively. The fatigue strength to stress ratios of $-1.0,-0.6,-0.3,0.1$, and 0.6 were measured by the up-and-down method. A PLG-100 C microcomputer-controlled high-frequency axial tension and compression fatigue testing machine was used, and the loading frequency is $120 \mathrm{~Hz}$. Mathematical statistics processed the fatigue test results, and the conditional fatigue limit with a $50 \%$ survival rate was calculated.

The $X$-ray diffraction technique was used to measure the residual stress of the unrelieved stress specimen. The measuring instrument used was Proto-i Xrd. For the $\mathrm{Cu}-\mathrm{K}_{\alpha}$ target, the collimating tube diameter of the ray generator tube is $1 \mathrm{~mm}$. The voltage is $24 \mathrm{kV}$, and the tube current is $4 \mathrm{~mA}$. The diffraction plane $\{114\}$ is fixed by the $\psi$ method of tilting, the $\psi$ angle is $0^{\circ}, 24^{\circ}, 35^{\circ}$, and $45^{\circ}$, respectively. The selected $<i>2$ ? (for the diffraction angle) are $153^{\circ}-161^{\circ}$, the step distance is $0.1^{\circ} / \mathrm{s}$, the single peak diffraction spectra at different angles were measured by the slow-scanning method, and the peak position was fitted by the crosscorrelation method. According to the linear fitting between $<i>2 \theta$ and $\sin ^{2} \psi$, the residual stress is calculated. Because the depth of $X$-ray penetration is small, only the residual stress on the material's surface can be measured. Therefore, the electropolishing corrosion technique is used to polish the surface of the sample, peel off layer by layer, and then, measure the residual stress at different depths. The surface residual stresses at different cycles were measured when the stress ratio $R$ was $-1.0,-0.6$, and 0.1 , respectively, and the distribution of residual stress with cyclic loading and its effect on fatigue strength are studied.

\section{Analysis of Test Results}

4.1. Fatigue Strength. The fatigue strength of the first specimen is higher than the predicted fatigue strength when the fatigue test is carried out by the up-and-down method, to determine the test stress level of the next specimen. The stress ratio and stress increment of the test remain unchanged until all tests are completed, and a set of passed or failed test data are obtained around the fatigue strength fluctuation. The test data are paired with the ascending and descending method as shown in Figure 3. The specimen is an unrelieved stress specimen, $R=-0.6$, in the air environment, at room temperature. The data are normalized to the effective yield strength. The median fatigue strength is calculated according to formula (1), fatigue strength with a $50 \%$ survival rate:

$$
\sigma_{50}=\frac{1}{M} \sum_{i=1}^{m} v_{i} \sigma_{i} .
$$

In the formula, $\sigma_{50}$ is the fatigue strength with a survival rate of $50 \%, M$ is the total number of effective specimens, $m$ is the stress series; $v_{\mathrm{i}}$ is the number of stress level tests of grade $i$; and $\sigma_{\mathrm{i}}$ is the stress level of grade $\mathrm{I}$.

According to the fatigue test results shown in Figure 4, the fatigue strength values of the stress-relieved and unrelieved specimens under various stress ratios are drawn into the Goodman life curve as shown in Figure 5. It can be seen that, with increased average stress, I. E., and the increase of stress ratio, the fatigue strength of titanium alloy shows a gradual decrease. The fatigue strength of the specimen without stress-relieving treatment is significantly higher than that of the treated one. However, for different stress ratios, the fatigue strength of the specimens with residual stress increased by $17.3 \%$ when $r=-1.0$, yet only $3.4 \%$ when $r=0.1$. However, when $r=0.6$, with the lack of stress constraint on the specimen surface and the easy influence of impurities and processing defects, fatigue cracks normally appear on the specimen surface, and the fatigue strength values of the two kinds of specimens are the same.

4.2. Observation of Fatigue Fracture. SEM observed fatigue fracture specimens. The stress-relieving specimens correspond to fatigue fracture surfaces with stress ratios $R$ of -1.0 , 
TABle 1: Chemical composition (mass fraction) of Ti-6Al-4V titanium alloy, \%.

\begin{tabular}{|c|c|c|c|c|c|c|c|c|c|c|}
\hline \multicolumn{9}{|c|}{ The main ingredient } & \multicolumn{2}{|c|}{ Other ingredients } \\
\hline $\mathrm{Ti}$ & $\mathrm{Al}$ & $\mathrm{V}$ & $\mathrm{Fe}$ & $\mathrm{C}$ & $\mathrm{Si}$ & $\mathrm{N}$ & $\mathrm{H}$ & $\mathrm{O}$ & Single & Summation \\
\hline The rest & 6.19 & 4.03 & 0.056 & 0.016 & $<0.39$ & 0.082 & 0.002 & 0.13 & $\leq 0.1$ & $\leq 0.4$ \\
\hline
\end{tabular}

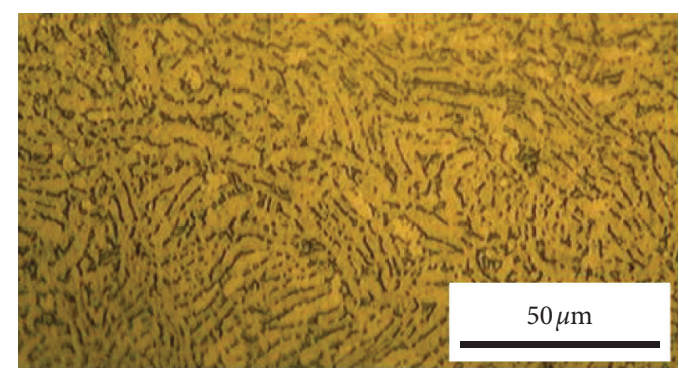

Figure 1: The microstructure of Ti-6Al-4V.

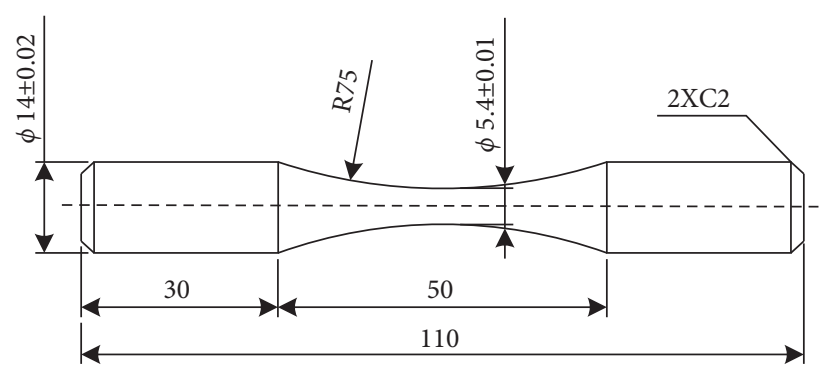

Figure 2: Fatigue specimen.

TABLE 2: Test results of roughness.

\begin{tabular}{lcr}
\hline Specimen & Ra $(\mu \mathrm{m})$ & Circumference direction \\
\hline FRS & Axial direction & 0.0658 \\
RS & 0.0195 & 0.0885 \\
\hline
\end{tabular}

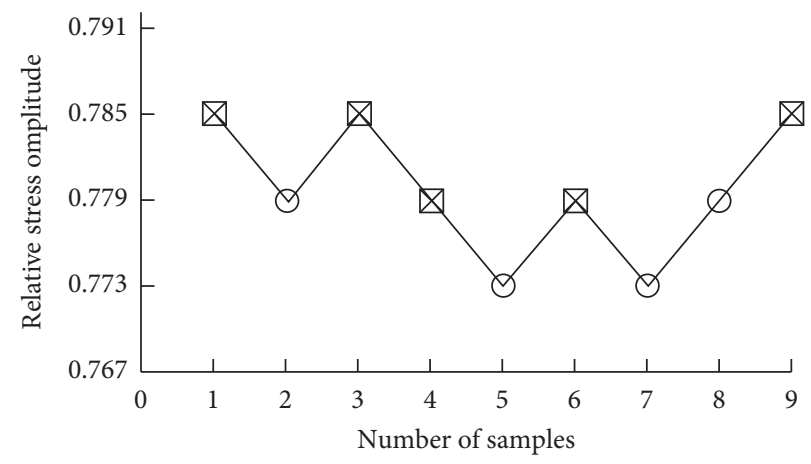

$\bigotimes$ Lose efficacy/effectiveness

Go through

Figure 3: Ti-6Al-4V fatigue up-and-down diagram $(R=0.6)$.

$-0.6,-0.3,0.1$, and 0.6 , respectively. The fatigue cracks start from the surface of the specimen, as shown in Figure 6. It can be found that the fatigue cracks all start from the surface of the crack, and the origin of the crack is a bright white spot.
It is found by observing the fatigue fracture surface of the unrelieved stress specimen that the location of fatigue initiation is different for different stress ratios, see Table 3. When the stress ratio $R$ is -1.0 and 0.6 , the fatigue crack 


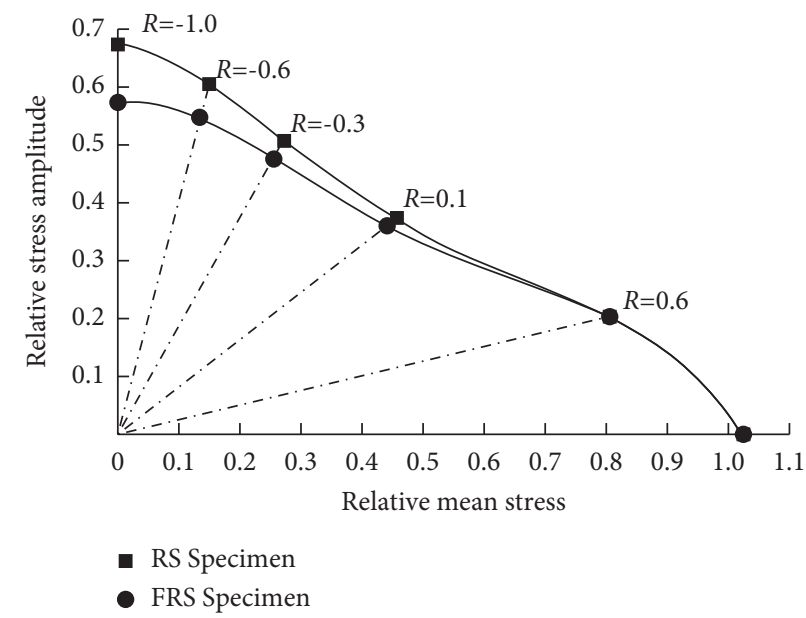

Figure 4: Ti-6Al-4V Goodman curves $\left(10^{7}\right.$ cycles) with residual stress and reduced stress.

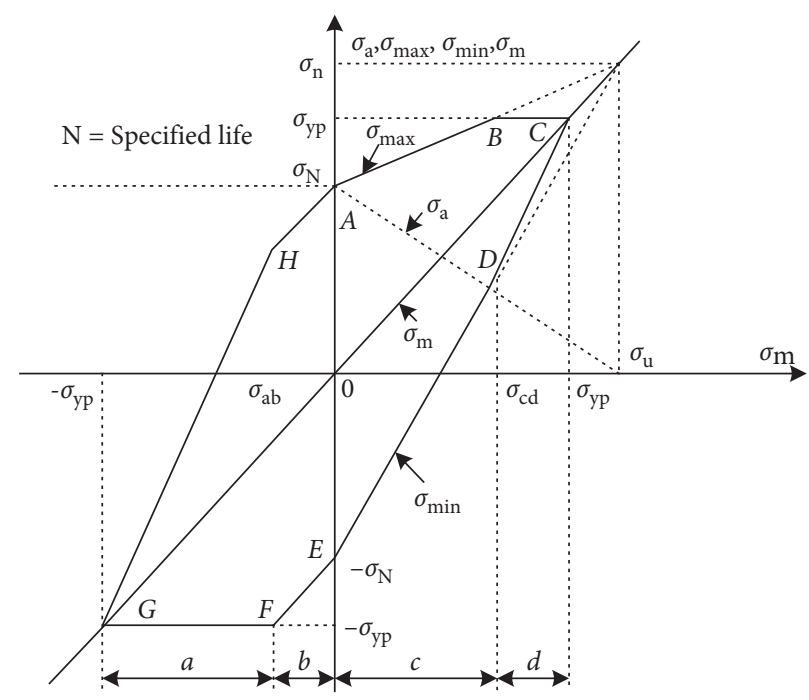

FIGURE 5: Goodman diagram indicates the relationship between the average stress and the maximum and minimum stress of a part subjected to alternating stress under the condition of equal life (equal number of cycles broken).

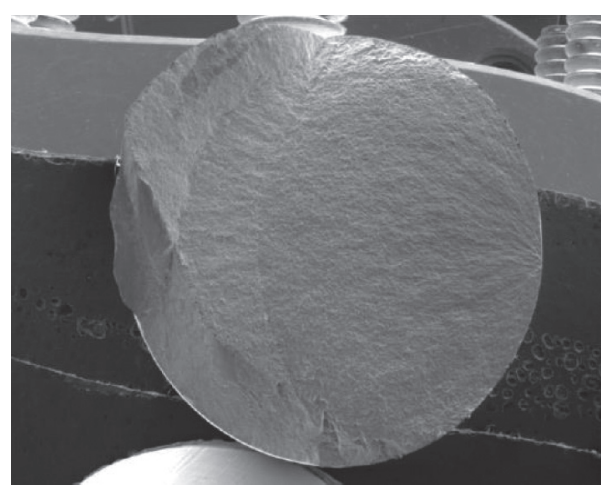

(a)

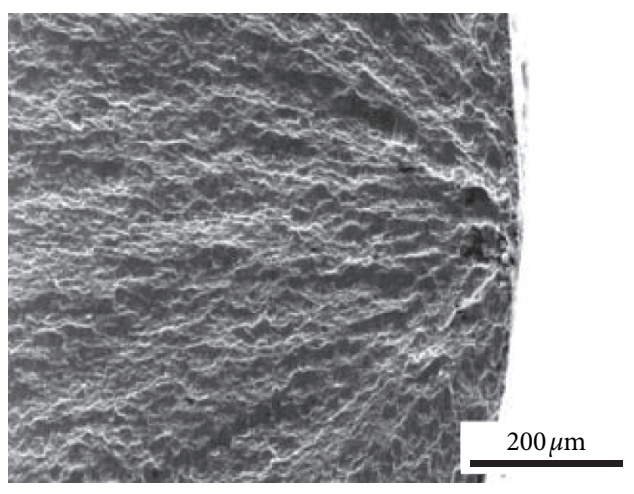

(b)

FIGURE 6: Variation of the fatigue fracture morphology of the stress-relieving specimen $\left(R</ \mathrm{I} \geq 0.1\right.$, stress amplitude $\sigma_{\mathrm{a}} \geq 340 \mathrm{MPa}$, and cycle number $N_{\mathrm{f}}=546278$ ). 
TABLE 3: Statistics of unrelieved stress samples at different fatigue initiation positions.

\begin{tabular}{lcccc}
\hline Where it started to crack & \multicolumn{4}{c}{ Stress ratio } \\
& -1.0 & -0.6 & -0.3 & 0.1 \\
\hline Surface & 4 & 2 & 2 & 1 \\
The internal part & 0 & 6 & 4 & 0.6 \\
\hline
\end{tabular}

initiation occurs on the surface and the direction of crack propagation is from the surface to the interior, as shown in Figure 7 . When the stress ratio $R$ is $-0.6,-0.3$, and 0.1 , most of the fatigue crack initiation occurs in the inner part of the specimen, i.e., the subsurface crack initiation, as shown in Figure 8 . The origin of the internal crack is a bright white zone, that is, the fisheye zone. Fatigue cracks extend radially from the source to the surroundings.

An enlarged view of the source of the internal fracture. The strongly reflective part (indicated by the arrow) is the small plane of the fracture, showing the characteristics of the physical fracture as shown in Figure 9. The composition of each element after energy spectrum analysis of the small plane at the crack initiation position is shown in Table 4. It can be seen that the mass fraction of $\mathrm{Al}$ is on the high side and the mass fraction of $\mathrm{V}$ is on the low side, yet $\mathrm{AL}$ is the most crucial $a$ phase-stable element in Ti-6Al-4V. From the analysis of the composition, it can be inferred that the region is mainly in the $a$ phase. The $a$ phase compared to the $\beta$ phase in Ti-6Al-4V is the soft phase, and the yield strength is low. The base $a$ plane is the main slip surface of the closely spaced hexagonal grains. Under high tensile stress, the fracture and separation of the $a$ phase lead to crack initiation. Therefore, the nucleation mechanism of the internal cracks in Ti-6Al$4 \mathrm{~V}$ can be considered the basal cleavage fracture of the $a$ grains.

\subsection{Effect of Stress Ratio on Residual Stress Relaxation.} During the test, to keep the surface compressive residual stress stable, all samples were processed by the same cutting parameters and cooling conditions. After the test, several samples were measured, and the results show that the residual compressive stress on the surface of the samples can reach $-500-400 \mathrm{MPa}$. After the sample is machined, the residual stress changes with the change of the surface depth, as shown in Figure 10. It can be seen from Figure 10 that the residual stress on the sample's surface is the largest. With the increase of the depth, the residual stress decreases gradually, and the depth of the residual compressive stress field is about $70 \mu \mathrm{m}$. In the absence of external forces, residual stress is a self-balanced distribution of the internal stress field in the structure, including the whole range of compressive stress and tensile stress in space. Therefore, the turning sample is an outer layer with immense residual compressive stress and a core with specific residual tensile stress.

The residual stress is not stable during the whole service period of the material structure, and the residual stress will relax and redistribute with the service process. The surface residual stresses at different cycles were measured by applying loads close to $10^{7}$ cycles with stress ratios $R=-1.0$, -0.6 , and 0.1 , respectively. As shown in Figure 11, the variation of residual surface stress with the number of cycles under different stress ratio $r$ fatigue limit load is shown. For the fatigue test with stress -1.0 , the residual stress decreased after the first cycle and decreased gradually with the increase in cycle numbers. When the cycle number reached 10 , the residual stress tended to be stable and remained at $-200 \mathrm{MPa}$. For the fatigue test with stress ratios $R</ \mathrm{I}>-0.6$ and 0.1, the relaxation of residual stress is not apparent, and the value of residual surface stress remains high in $10^{7}$ cycles. It can be seen that the relaxation degree of residual stress in Ti-6Al-4V machining depends on the relationship between the local superposition stress (the initial residual stress and the vector superposition of the applied load) and the yield strength of the material. When a fatigue load with a stress ratio of -1.0 is applied, the residual compressive stress on the surface of the specimen is superimposed on the minimum stress, and when the composite stress exceeds the compressive yield strength of the material, local plastic deformation occurs. The stress state redistributes, and the residual stress relaxes. When the average stress is the fatigue load of tensile stress, the residual stress does not relax if the local superimposed load does not exceed the yield strength.

\subsection{Effect of Stress Ratio and Residual Stress on Fatigue} Initiation. In the test, the applied fatigue load is of medium stress level and the number of cycles is $10^{6} \sim 10^{7}$. All the fatigue cracks of the specimen after stress relief treatment originate from the surface. It is generally stated that the maximum stress corresponding to the cycle number $10^{7}$ is the fatigue limit, and the curve of the relationship between stress and fatigue life $n$ is shown in Figure 12. However, there is high residual compressive stress on the surface of the sample without heat treatment. When the stress ratio is -1.0 , after several cycles, the residual stress on the outer surface sharply decreased and ultimately remained at -200MPA. Under the action of free surface, the initiation of fatigue crack is located on the free surface. Once the crack appears, due to the existence of compressive stress, the crack closes, and more fatigue cycles are consumed before the crack initiation and stable propagation, and the fatigue life is significantly increased. When the stress ratio is $-0.6,-0.3$, or 0.1 , the average stress of the surface layer reduced due to the high residual stress on the surface. With the increase of the stress ratio, the residual stress in the crack may change from compressive stress to tensile stress. The high residual compressive stress on the outer surface has only a small effect on the inner crack propagation, so the acceleration of the fatigue life shows a gradual decrease. When the stress ratio is 0.6 , the residual stress of the specimen relaxes rapidly. After several cycles, the residual stress basically disappears. Like the specimen without residual stress, the 


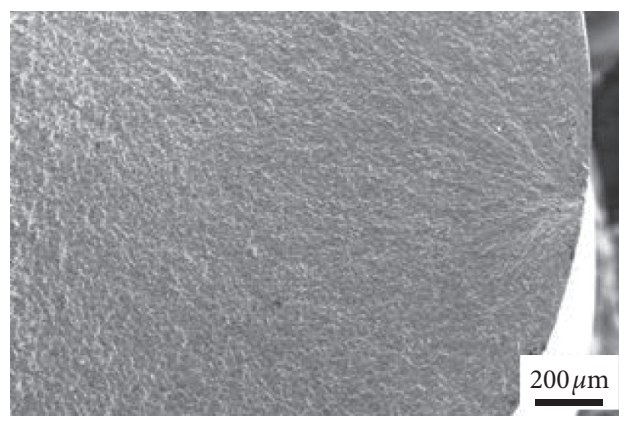

(a)

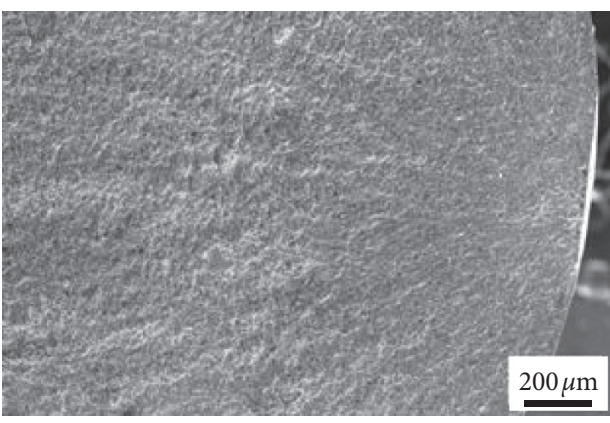

(b)

FIGURE 7: Fatigue fracture surface of the specimen with residual stress. (a) $R=1.0, \sigma_{\mathrm{a}}=615 \mathrm{mpa}$, and $N_{\mathrm{f}} \geq 2581250$. (b) $R=0.6, \sigma_{\mathrm{a}} \geq 184 \mathrm{mpa}$, and $N_{\mathrm{f}} \geq 9447144$.

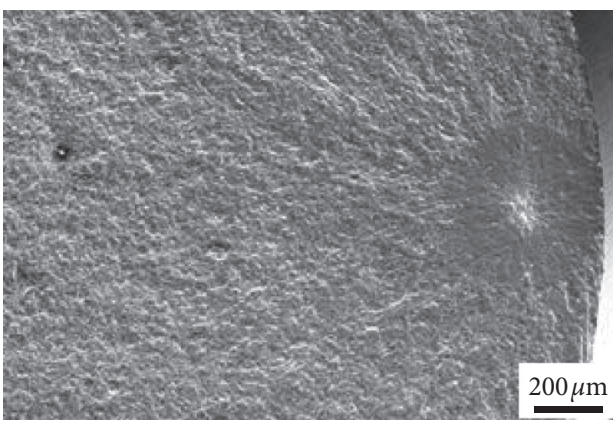

(a)

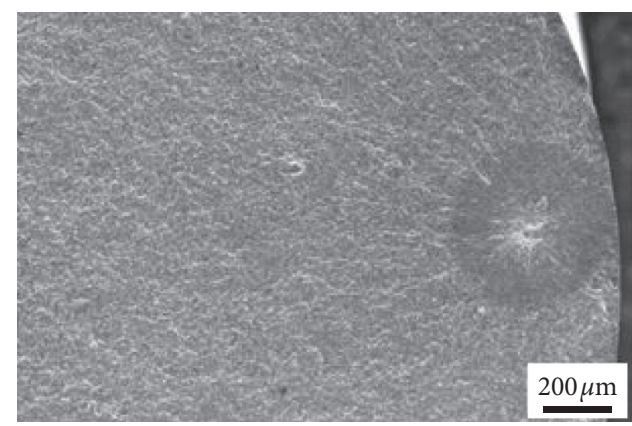

(b)

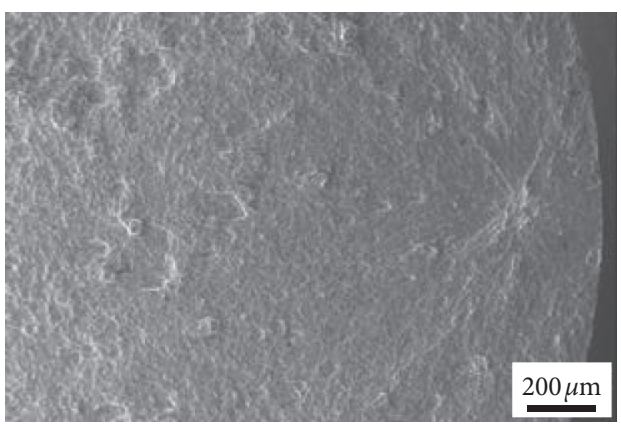

(c)

Figure 8: Fatigue fracture surface of the specimen with residual stress. (a) $R=-0.6, \sigma_{\mathrm{a}} \geq 552 \mathrm{MPa}$, and $N_{\mathrm{f}} \geq 4230323$. (b) $R=-0.3$, $\sigma_{\mathrm{a}} \geq 458 \mathrm{MPa}$, and $N_{\mathrm{f}} \geq 9780627$. (c) $R</ \mathrm{I} \geq 0.1, \sigma_{\mathrm{a}} \geq 342 \mathrm{MPa}$, and $N_{\mathrm{f}} \geq 9565303$.

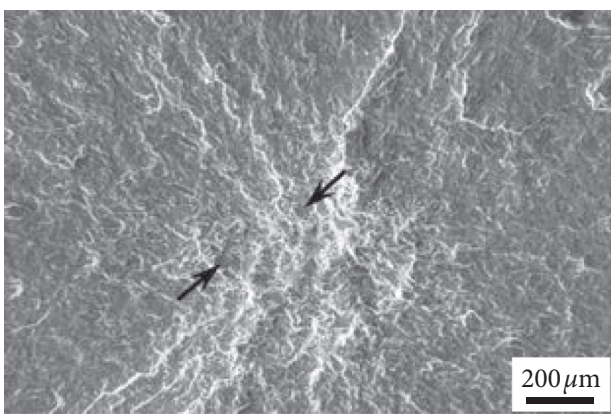

FIgURE 9: Enlarged view of internal origin $(R=0.1)$. 
TABLE 4: The composition of the small plane of the crack initiation, \%.

\begin{tabular}{lccc}
\hline Element & Mass fraction & Atomic fraction & Relative error \\
\hline Titanium & 90.74 & 86.35 & 3.8 \\
Aluminium & 6.75 & 11.41 & 0.3 \\
Vanadium & 2.51 & 2.24 & 1.8 \\
Total & 100 & 100 & -- \\
\hline
\end{tabular}

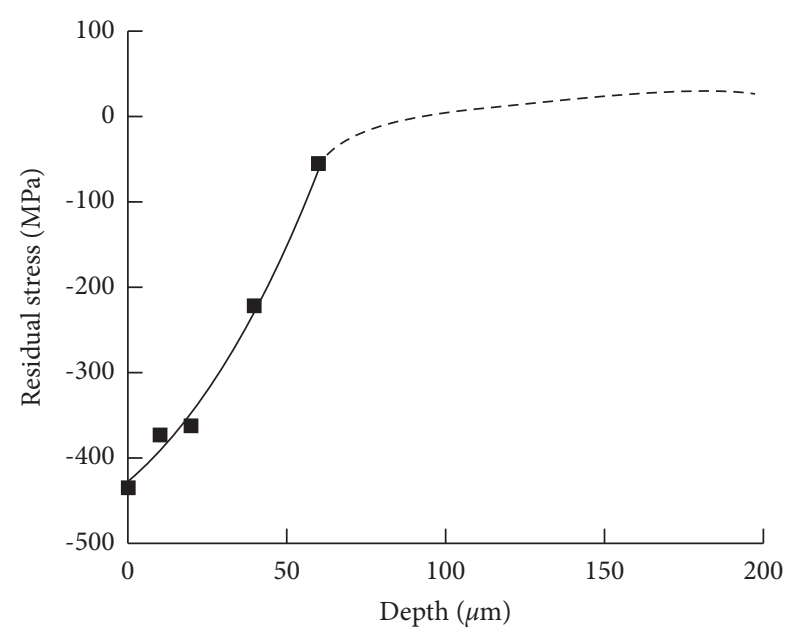

Figure 10: Curve of residual stress distribution.

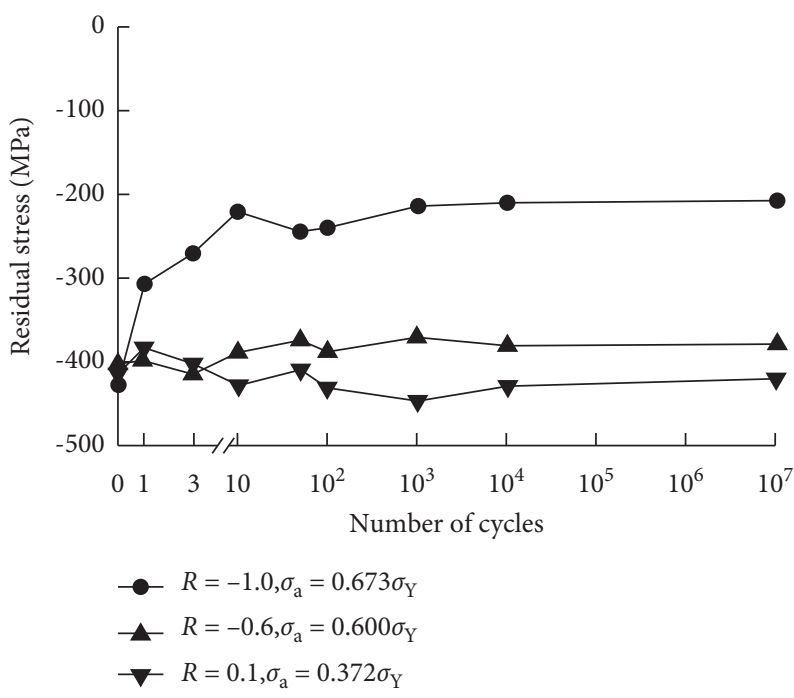

FiguRE 11: Relaxation of surface residual stress with the number of cycles under different stress ratio $R$ fatigue limit load $\left(\sigma_{\mathrm{Y}}\right.$ is the normalization factor).

crack starts at the outer surface and the fatigue life is generally the same.

The results show that the fatigue limit of the specimens with residual stress is increased by $17.4 \%$ and $3.4 \%$, when $R=-1$ and 0.1 , respectively. When $R</ I \geq 0.6$, the fatigue limit values of the two kinds of specimens are the same. The cyclic fatigue strength of $R=-1$ increases by about $17.4 \%$, and with the increase of stress ratio, the effect of residual stress on fatigue strength declines gradually until it is reduced to 0 . When the stress ratio is -1 , the residual stress has the greatest influence on the fatigue strength. With increased stress ratio, the residual compressive stress increases the fatigue life, but the residual compressive stress relaxes more quickly when the stress ratio is lower. The reason may be as follows: when the stress ratio is -1 , after several cycles, the residual stress on the outer surface has been reduced obviously and remains at $-200 \mathrm{MPa}$. At this time, the crack initiation is still located on the free surface. Once the crack appears, due to the existence of compressive stress, the crack closes, and more fatigue cycles are consumed before the 


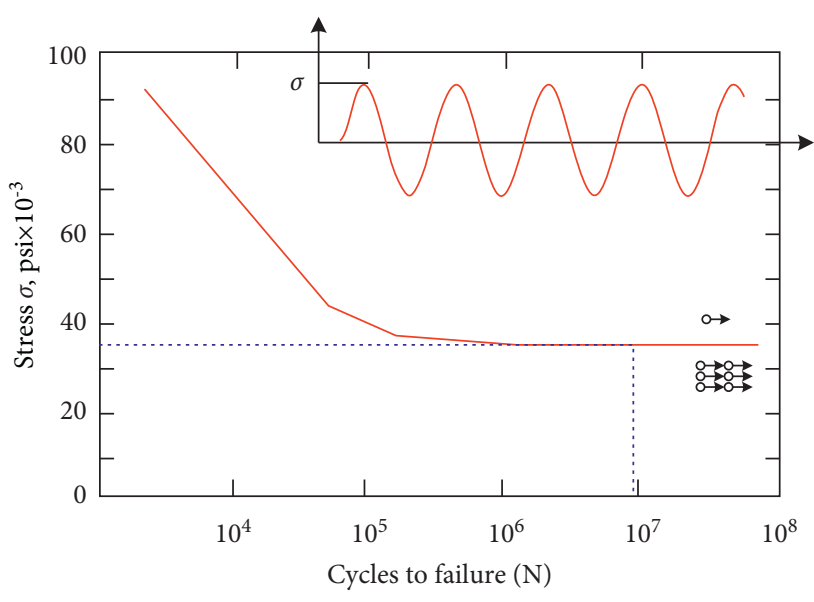

Figure 12: S-N curve.

crack nucleation and stable propagation, which contributes to the remarkable increase in the fatigue life. With the increase of the stress ratio, not only the crack initiation location moves inwards but also the distribution of residual stress changes dramatically due to the crack initiation. Even though the residual compressive stress on the outer surface is very high, the residual stress at the crack initiation location may change from compressive stress to tensile stress with increased stress ratio, and the high residual compressive stress on the outer surface can only have a little effect on the crack propagation. Therefore, the degree of increasing fatigue life drops steadily. When the stress ratio is increased, the residual stress of the specimen relaxes rapidly. After several cycles, the residual stress basically disappears. Like the specimen without residual stress, the crack starts at the outer surface and the fatigue life is generally the same.

\section{Conclusions}

5.1 The surface residual compressive stress caused by machining can effectively improve the fatigue strength of $\mathrm{Ti}$ $6 \mathrm{Al}-4 \mathrm{~V}$ specimens and is closely related to the stress ratio. When the stress ratio $R=-1.0$, the residual compressive stress on the cutting surface can increase the fatigue strength by about $17.3 \%$. With the increase of the stress ratio, the effect of the residual compressive stress on the cutting surface decreases gradually, and the residual compressive stress disappears when the stress ratio is 0.6.

5.2 The fatigue fracture of stress-relieving specimens originates on the surface; when the stress ratio is $-0.6,-0.3$, and 0.1 , the unrelieved fatigue cracks begin at the inner phase grains, and when the stress ratio is -1.0 and 0.6 , the fatigue cracks begin at the surface.

5.3 The effect of surface residual compressive stress on the fatigue strength of $\mathrm{Ti}-6 \mathrm{Al}-4 \mathrm{~V}$ and the initiation position is related to the stress ratio. When $R=-1.0$, the influence of the residual stress on the fatigue strength is mainly due to the closing effect of the surface crack, and when $R=-0.6-0.1$, the surface residual compressive stress leads to a decrease in the average stress in the surface layer of the specimen, which causes fatigue crack initiation inside, and the fatigue strength of titanium alloy is mainly controlled by internal defects and local stress concentration.

\section{Data Availability}

The data used to support this study are available from the corresponding author.

\section{Conflicts of Interest}

The authors declare no conflicts of interest regarding the publication of this paper.

\section{Acknowledgments}

This work was supported by the Anhui Province University Natural Science Key Research Project in 2017 (grant no. KJ2017A750) and in 2020 (grant no. KJ2020A1118); 2019 Anhui Province, characteristic high-level specialty: Machinery Design and Manufacture Specialty Construction Project (grant no. 2019tgzy01); and 2020 Anhui provincial demonstration teaching course "machine tool technology" project (grant no. 2021sfk01).

\section{References}

[1] Qu Jian-hui, "Numerical method for martensitic transformation of Ti-6Al-4V alloy and its application in simulation of high speed cutting process," Master's thesis, Beijing Institute of Technology, Beijing, China, 2015.

[2] C. Leyens and M. Peters, Titanium and Titanium Alloys, Wiley-VCH Verlag Gmbh \& Co. Kga:A, Weinheim, 2003.

[3] R. R. Boyer, "An overview on the use of titanium in the aerospace industry," Materials Science and Engineering: A, vol. 213, no. 1-2, pp. 103-114, 1996.

[4] K. Tokaji, "High cycle fatigue behaviour of Ti-6Al-4V alloy at elevated temperatures," Scripta Materialia, vol. 54, no. 12, pp. 2143-2148, 2006.

[5] J. Zachary, P. Kochis, and R. Narula, Steam Turbine Design Considerations for Supercritical Cycles, 2007, http://www. bechtel.com/assets/files/Tech Papers/steam-turbine.doc" title=". http://www.bechtel.com/assets/files/Tech Papers/steam-turbine. doc">. http://www.bechtel.com/assets/files/Tech Papers/steamturbine.doc.

[6] H. Oguma and T. Nakamura, "The effect of stress ratios on very high cycle fatigue properties of Ti-6Al-4V," Key Engineering Materials, vol. 261-263, pp. 1227-1232, 2004.

[7] K. S. Chan, "Roles of microstructure in fatigue crack initiation," International Journal of Fatigue, vol. 32, no. 9, pp. 1428-1447, 2010.

[8] K. S. Chan and Y.-D. Lee, "Effects of deformation-induced constraint on high-cycle fatigue in $\mathrm{Ti}$ alloys with a duplex microstructure," Metallurgical and Materials Transactions A, vol. 39, no. 7, pp. 1665-1675, 2008.

[9] I. Bantounas, D. Dye, and T. C. Lindley, "The effect of grain orientation on fracture morphology during high-cycle fatigue of Ti-6Al-4V," Acta Materialia, vol. 57, no. 12, pp. 3584-3595, 2009.

[10] M. Benedetti and V. Fontanari, "The effect of bi-modal and lamellar microstructure of Ti-6Al-4V on the behavior of fatigue cracks emanating from edge-notches," Fatigue and Fracture of Engineering Materials and Structures, vol. 27, no. 3, pp. 1073-1089, 2004. 
[11] L. Wagner and G. Lutjering, "Influence of surface treatments on fatigue strength of Ti-6Al-4V," Gefüge und Bruch, pp. 233-245, 1988.

[12] R. Morrissey, D. L. Mcdowell, and T. Nicholas, "Frequency and stress ratio effects in high cycle fatigue of Ti-6Al-4V," International Journal of Fatigue, vol. 21, no. 7, pp. 679-685, 1999.

[13] J. A. Ruppen, C. L. Hoffmann, V. M. Radhakrishnan, and A. J. McEvily, "The effect of environment and temperature on the fatigue behavior of titanium alloys," Fatigue Env. and emperature Effects, pp. 265-300, 1980. 